\title{
Grace Natalie Louisa
}

\section{Adib Rifqi Setiawan}

$\Lambda$ lobatnic Research Society $(\Lambda \mathrm{RS})$

Jl Kudus - Colo, km. 19, Pandak 001/003, Colo, Kudus, 59353, Indonesia

adibrifqisetiawan@gmail.com

\begin{abstract}
Abstrak
Artikel berikut menyajikan obrolan dengan Grace Natalie Louisa tentang pengalaman tampil di For Him Magazine (FHM), perjuangan toleransi, transparansi dan disrupsi parlemen, pentingnya digitalisasi untuk perkembangan pengelolaan negara Indonesia, hingga asal usul sapaan 'bro' dan 'sis' yang dipakai dalam Partai Solidartitas Indonesia (PSI).
\end{abstract}

Kata-kata Kunci : Grace Natalie Louisa; Partai Solidartitas Indonesia;

\section{Pengantar}

Grace Natalie Louisa adalah seorang Ketua Umum Partai Solidaritas Indonesia (PSI), seorang mantan jurnalis, seorang istri, dan seorang Ibu yang lahir pada 4 Juli 1982 . Grace menyelesaikan sekolah dasar di SD Kristen IPEKA Sunter serta pada 1994. Sekolah menengahnya diselesaikan di SMAK 3 BPK Penabur, Jakarta. Grace kemudian mengambil jurusan akuntansi di Institute Bisnis dan Informatika Indonesia. ${ }^{123}$

Pengalaman pertamanya di dunia jurnalistik adalah ketika jaringan SCTV mengadakan SCTV Goes to Campus, kompetisi untuk mencari mahasiswa yang ingin menjadi jurnalis. Grace memenangkan kompetisi tingkat provinsi (DKI Jakarta) dan kemudian mencapai lima besar secara nasional.

Setelah menyelesaikan kuliah, Grace direkrut oleh SCTV dan menjadi presenter pada acara Liputan 6. Pada tahun-tahun awal sebagai jurnalis televisi, ia meliput kejahatan, politik, bisnis, dan berita terkini lainnya. Dia mengatakan sulit beradaptasi dengan dunia televisi yang sangat dinamis dengan jam kerja yang tidak dapat diprediksi. Tapi itu tidak menyurutkan semangatnya, dan dia perlahan-lahan jatuh cinta dengan dunia jurnalisme. Setelah setahun, dia pindah ke ANTV dan kemudian ke tvOne.

Pengalaman sebagai jurnalis membuat Grace dekat dengan isu politik. Kedekatannya ke isu politik berlanjut, tahun 2012, Grace dipercaya menjadi CEO di Saiful Mujani Research and Consulting (SMRC). Beberapa momentum politik penting dilewatinya bersama SMRC, termasuk Pemilihan Legislatif dan Presiden 2014.

Grace memantapkan diri untuk terjun langsung ke dunia politik dan memimpin PSI karena ingin 'Rumah Indonesia' yang akan dihuni oleh kita, anak-anak kita, saudara kita di masa yang akan datang, adalah Indonesia yang menjadi rumah damai buat seluruh suku, golongan, agama, ras dan keyakinan.

\footnotetext{
(Setiawan, Amazing Grace, 2018)

2 (Setiawan, Grace Natalie, PSI, Poligami, 2018)

3 (Setiawan, Q \& A. Grace Natalie Louisa. [interview], 2019)
} 
Berikut ini obrolan dengan Grace Natalie Louisa tentang pengalaman tampil di For Him Magazine (FHM), perjuangan toleransi, transparansi dan disrupsi parlemen, pentingnya digitalisasi untuk perkembangan pengelolaan negara Indonesia, hingga asal usul sapaan 'bro' dan 'sis' yang dipakai dalam PSI.

\section{Pada 2009 lalu, For Him Magazine (FHM) menerbitkan artikel dan foto Anda yang waktu itu dipilih menjadi 1 dari 100 wanita terseksi versi. Bagaimana tanggapan Anda tentang hal ini?}

Saya memang pernah berfoto untuk majalah For Him Magazine (FHM) Indonesia dengan pose di atas meja rapat, tapi itu masih berbaju lengkap lho. Posenya sensual tapi nggak porno. Memang kesannya liar banget sih saya berpose di atas meja, kayak mau menerkam, hahaha. Waktu itu saya menelepon reporternya dan bilang, "Mas kayaknya itu jangan deh, seksi banget." Akhirnya mereka setuju sih nggak naikin yang itu. Tahun 2009 saya dipilih jadi 1 dari 100 wanita terseksi versi FHM Indonesia dan katanya di tahun depannya peringkat aku naik. Okelah kalau saya dibilang orang menarik, tapi kalau seksi kan konotasinya berarti harus ada bagian-bagian tertentu itu yang ukurannya lebih besar dari pada yang standar. Dimana seksinya saya? Saya pakai baju seksi sedikit saja, pasti sudah dikomplain, katanya sih begitu, tapi waktu itu saya tanya balik, "Yakin? Bukannya para cowok itu suka merasa terintimidasi sama wanita yang pintar?" Menurut saya wanita pintar itu cenderung mengintimidasi bagi kebanyakan pria.

\section{Sebelum terjun ke dunia politik, Anda merintis karir sebagai jurnalis televisi, Apa yang menggerakkan Anda untuk mengubah sistem dari dalam?}

Dulu kerja jadi jurnalis malah tidak menikmati dunia politik. Tapi ini berubah saat saya melihat Pak Jokowi sampai di Jakarta dan beliau merubah Jakarta dalam waktu singkat. Saya yang tadinya tidak peduli dengan politik tersentuh dengan politik baik dalam hidup seharihari. Mulai dari mengurus surat di kelurahan, saya dulu menikah di tahun 2011, terasa sekali mengurus surat di kelurahan ribet, nunggunya lama, pegawainya suka tidak ada, bolak-balik hanya untuk mengurus surat pengantar dan sebagainya. Begitu diubah oleh Pak Jokowi, langsung terasa. Setelah itu saya mengurus E-KTP, perbedaannya terasa sekali sebelum dan sesudahnya. Para pegawai mentalnya melayani, sampai memberikan nomor WhatsApp. Dulu harus cek berkali-kali, bolak-balik dan belum tentu sudah jadi. Hal kecil saja berubah. Kemudian banyak perubahan terjadi di Jakarta, jadi lebih bersih, baru ketahuan, banyak borok-boroknya. Misalkan, mengapa kita suka banjir? Karena tidak dibersihkan. Saya pernah membaca berita, dulu kan di Jl. Gunung Sahari Raya setiap hujan pasti banjir, ternyata sudah 20 tahun tidak dibersihkan, ya bagaimana tidak banjir? Dari situ saya berkesimpulan, kita mempunyai masalah human resources. Kalau pemimpin kita bagus, mempunyai kemampuan, mau kerja, pasti terurus. Tapi kalau human resources-nya jelek ya itu masalahnya sekarang kan? Karena orang-orang bagus saat ini tidak mau masuk politik. Jadi di situ punya harapan, saya mulai mengerti masalah-masalahnya, ditambah lagi setelah melihat Pak Jokowi berarti kita sebenarnya bisa lebih baik. Asal human resources nya dibenahi.

Kedua, saya menyadari kok kita semakin banyak mendengar peristiwa intoleransi? Kalau sekarang apa lagi, tambah sering. Paling tidak setiap bulan pasti kita dengar kasus, dulu masih jarang-jarang. Jadi saya juga ingin do something, melawan intoleransi. Karena dengan kondisi kita yang beragam, yang namanya toleransi dan solidaritas itu modal dasar. Kalau tidak ada itu, bagaimana kita bisa hidup berdampingan? Apalagi kita semua berbeda-beda. Suku ada 700 lebih, agama yang diakui ada enam, belum lagi penghayat, kepercayaan. Nah, 
kalau tidak ada toleransi, kita akan meniadakan satu dengan lainnya, dan kita akan ribut terus. Bagaimana mau membicarakan kemajuan ekonomi, kalau hak untuk hidup dengan aman; tidak diusir, tidak ditolak, tidak dikeroyok massa saja tidak terjamin dengan baik?

\section{PSI menyebut diri sebagai partai yang progresif dengan kebijakan-kebijakan yang masih terlihat kontroversial bagi banyak pelaku politik konservatif yang masih aktif di DPR. Darimana keberanian ini datang? Dan bagaimana perjuangannya selama ini?}

Yang kami usulkan dan yang kita lakukan itu sudah terjadi di swasta kalau kita lihat. Jadi begini, setelah saya dan teman-teman mulai tercerahkan dengan politik yang baik, saya jadi mulai banyak pertanyaan. Kalau kita mau mendapat orang bagus, berarti recruitment-nya harus bagus, institusi-nya juga harus bagus. Kalau saya kuliahnya akuntansi dulu, yang bagus itu institusinya "Price Waterhouse Cooper", atau "Ernst \& Young" dan lulusan-lulusan semuanya lomba mau ke sana. Kalau sudah lulus dari sana, pasti bagus. Sekarang "Ernst \& Young" kan tes masuknya susah, jadi benar-benar mau mencari yang terbaik. Karena sudah memiliki management yang seperti itu, makanya orang-orang terseleksi sendiri. Yang bodoh dan malas ya tidak berani daftar ke sana, sementara yang bagus-bagus pasti mendaftar dan tahu kalau mereka akan punya kesempatan. Bahkan orang biasa saja bisa sampai jadi partner, karena memang ada jenjang yang jelas, ada penilaian yang jelas.

Nah, kenapa itu tidak ada di politik? Padahal di swasta sudah seperti itu. Kenapa tidak ada satupun partai yang melakukan perekrutan caleg secara terbuka? Semuanya tertutup. Karena tertutup, asik saja. Masukkan istrinya, anaknya, temannya. Bukannya tidak boleh istri dan anaknya masuk, kalau bagus tentu boleh. Tapi harus ada seleksi yang terbuka sehingga jelas. Kalau anaknya masuk dan ada orang lain yang tidak masuk, kenapa? Benar tidak anaknya lebih bagus daripada orang tersingkir itu? Jangan sampai ada orang bagus yang kalah karena saingan dengan anak owner. Kejadian seperti itulah yang membuat orang-orang frustasi dan tidak mau masuk politik. Apalagi anak-anak muda yang sudah terbiasanya semuanya serba transparan. Sekarang saja kalau kita mau pesan makanan, yang kita andalkan apa? Rating orang dan komen. Jadi kita tahu kurang lebih ini enak meskipun kita tidak tahu. Nah, jadi sudah se-terbuka itu bahkan untuk pesan makanan, masa untuk seleksi anggota dewan tidak pernah terbuka? Itu satu.

Kami progresif karena yang lainnya sangat old school, jadul, purba bahkan. Apa yang kita lakukan, kita cuma melihat kalau di dunia swasta sudah praktik yang sangat biasa, tapi mengapa di sektor publik tidak? itu simple logic saja sih, bukan rocket science. Lalu kalau semuanya bisa serba transparan dalam kinerja, kita sebagai pekerjanya punya KPI (Key Performance Index), mengapa di DPR tidak? Makanya kita ingin masuk ke sana untuk melakukan digitalisasi parlemen.

Jadi yang PSI usulkan, kita lihat dulu problem-nya, orang-orang suka bolos, orang suka tidur, lalu produktivitas rendah. Undang-undang tahun 2018 yang beres hanya lima, padahal targetnya 50. Nah, bayangkan. Kalau kita kerja di kantor, gaji dibayar tetapi tidak pernah masuk, kalaupun masuk tidur, lalu dari tugas yang diberikan, kita hanya menyelesaikan $10 \%$, kira-kira apa yang terjadi? Ya dipecat. Padahal kita hanya merugikan perusahaan, nah kok bisa orang yang di DPR, mengurus 260 juta rakyat Indonesia, ia punya tugas undang-undang anggaran, kok bisa seenak-enaknya tidur dan kita tidak pernah - sepanjang saya jadi wartawan ya - tidak pernah meliput, mendengar ada anggota dewan yang terkena sanksi karena kelakuan tersebut. Bahkan kerap kali kalau ada kasus, dilaporkan ke MKD (Mahkamah Kehormatan Dewan) paling hanya teguran. 
Selain itu, tidak ada reward and punishment, orang bolos, orang rajin, sama saja. Jadi, untuk yang rajin juga terdemotivasi, semua yang mereka terima sama saja dengan yang malasmalasan. Tidak masuk akal. Nah, kita ingin masuk kesana dengan mengadakan transparansi. Kita ingin membuat semuanya live, wajib. Kalau sedang rapat, kunjungan kerja, pas reses ada aktivitas, semua dilaporkan dengan live. Jika tidak ada live-nya, berarti bolos. Kalau bolos lebih dari 10\%, langsung dipecat by system. Itulah sistem yang kami buat, jadi orang bisa tahu, agenda saya hari ini rapat dengan siapa, ketemu siapa, semua ada. Kan kerja untuk masyarakat, bosnya masyarakat, masa bos kita tidak tahu kita ngapain? Kan tidak mungkin.

Bagaimana mungkin ada orang yang digaji begitu tinggi tetapi tidak ada laporan kinerja? Ada istilah "if you give peanuts, you get monkeys", tapi kita kan tidak give peanuts, kita memberikan kompensasi yang bagus, anggota dewan akan dapat pensiun seumur hidup. Jika Tsamara (Amany) terpilih, dia akan dilantik umur 22 tahun, jika dia menjabat 5 tahun, di umur 27 dia akan mendapatkan pensiun seumur hidupnya. Gaji juga jauh dibanding kerja manager bank sekalipun, mereka bisa mengumpulkan 2-3 Miliar bahkan lebih per tahun. Sudah begitu bagusnya, mengapa kita masih dapat monkeys?

PSI ingin semua rapat disiarkan live. Kalau sambil live nanti terlihat saat ruangan kosong, orang di sebelah kita tidur, apalagi kalau ketiduran pulas. Semua akan terlihat dari kamera PSI. Kita juga buat fitur penilaian, mirip jasa Go-Jek atau Grab. Masa anggota Dewan kalah dengan tukang Go-Jek dan juga Grab? Makanya kita ingin masuk kedalam untuk membuat disrupsi. Karena kita tidak bisa mengatakan ke mereka bahwa cara mereka selama ini salah dan menggurui, itu percuma. Daripada begitu, lebih baik kita sendiri masuk ke situ, terapkan apa yang kita usulkan pada diri sendiri. Itulah yang dikatakan disrupsi, karena yang tadinya standarnya dibawah, mau tidak mau jadi ikut standar PSI.

Masyarakat yang tadinya tidak tahu, nanti akan melihat kalau anak-anak PSI bisa, kenapa yang lain tidak? Selanjutnya standarnya akan naik. Masyarakat akan meminta kita untuk lebih transparan. Akhirnya, pilihan para dewan ini tinggal dua. Pertama, mereka harus berubah dan ikuti standar yang PSI buat, semuanya transparan. Kalau tidak dilakukan yang terjadi adalah skenario kedua, ditinggal pemilihnya. Kalau mereka ditinggal pemilihnya, kita akan memiliki lebih banyak orang yang mau bekerja dengan standar itu. Mau opsi apapun yang terjadi, yang diuntungkan siapa? Masyarakat. Kalau yang lama-lama ini berubah, kerjanya menjadi lebih bagus, kita semua diuntungkan. Kalau tidak berubah, itu namanya hukum alam. Kalau kita meminta yang sekarang berubah? Susah. Yang bisa kita lakukan adalah edukasi market-nya, sama seperti Go-Jek, dia edukasi masyarakatnya. Jadi standar masyarakat yang ditingkatkan. Inilah yang ingin PSI lakukan di parlemen.

\section{Sebagai seorang pelaku politik beragama minoritas, menurut Anda, apa yang bisa kita lakukan sebagai negara untuk membantu melawan diskriminasi terhadap sesama?}

Harus masuk dalam regulasi. Kenapa? Karena selama 20 tahun terakhir, yang melakukan diskriminasi itu adalah negara sendiri. Dalam hal ini, pemerintah daerah. Dr. Michael Buehler adalah guru besar ilmu politik dari Northern Illinois University, dia melakukan penelitian tentang perda Syariah di Indonesia, dan dia mendapati ada 440 perda Syariah tersebar di berbagai provinsi, kabupaten di Indonesia. Ternyata, yang membuat perda-perda tersebut 
adalah partai politik yang berhaluan nasionalis. Jadi dia sempat membuat artikel berjudul Partainya Sekuler, Aturannya Syariah. ${ }^{4}$

Ketika negara melakukan diskriminasi, itu bahaya. Misalnya, sekolah negeri kan campur siswanya, namun semua siswi harus mengenakan busana Muslim, bahkan harus bisa baca tulis Al-Qur'an untuk menjadi syarat kelulusan, sekalipun ia non Muslim. Itu perda Syariah. Perda Injil pun juga bermasalah. Misalnya di Wamena, dalam rangka membuat orang lebih rajin ke gereja, pada hari minggu dibuat aturan tidak boleh berjualan sebelum jam 5 sore, supaya harapannya orang rajin ke gereja. Ternyata, begitu aturan diterapkan, sama saja. Yang ke gereja jumlahnya sama saja. Kalau malas ya memang malas, dan ini peraturannya diskriminatif kan. Orang mau mencari nafkah jadi tidak bisa, dilarang. Meskipun dia pedagang non-Kristen, dia tidak ke gereja tetap saja dilarang. Orang lain yang non-Kristen juga tidak bisa jajan, kan diskriminatif. Ketika kita membuat produk hukum hanya mengambil nilai agama, tentu saja kita pasti akan diskriminasi yang lainnya. Itulah salah satu hal yang PSI perjuangkan, mengapa kita tidak membuat perda Pancasila saja? Jika kita membuat perda Pancasila seperti Undang-undang Dasar 1945 semuanya akan tercakup, tanpa kecuali.

Bahayanya perda-perda agama yang sudah berlangsung lebih dari 20 tahun (mulai dari Otonomi Daerah tahun 1999), orang jadi terbiasa dengan narasi "Yang sedikit harus ikut dengan yang banyak". Narasi ini sudah berlangsung selama 20 tahun, akhirnya sekarang kalau ada peristiwa intoleransi, narasi itu yang terus ada. Contoh, kemarin di Dusun Karet, Bantul. Pak Slamet ditolak tinggal disana karena ia non-Muslim sementara penduduk Muslim. Jadi, ditolak karena mayoritas bukan seperti dia. Dalam semua seperti peristiwa ini, yang kami kritisi, mengapa tidak ada kekuatan politik yang resmi menolak itu? Dalam arti, Ketua Umum, Sekretaris Jenderal, atau juru bicara resmi partai melakukan penolakan, pengecaman terhadap aksi-aksi diskriminasi dan intoleransi. Ketika semua diam, akhirnya menurut masyarakat it's okay seperti itu. Dua puluh tahun berjalan yang tadinya merupakan sesuatu yang tidak normal, lama-lama menjadi standar normal yang baru. Inilah bahayanya yang kami sebut "normalisasi intoleransi". Itu bahayanya jika toleransi tidak diperjuangkan, kita suarakan, jika semua diam karena tidak mau berlawanan dengan kelompok intoleran, ya semakin besar jumlahnya. Kalau kita tidak mau berjuang, tunggu saja salah satu dari kita akan menjadi korban, dan tinggal tunggu saja NKRI ini pecah. Papua mau sendiri, NTT sendiri, Sulawesi Utara juga mau sendiri, bahkan mungkin Aceh mau sendiri karena standar disana sangat berbeda dengan pulau Jawa. Kalau dikatakan Indonesia bubar, ya itu yang dimaksud - ketika orang mau-maunya sendiri, menurut keinginan mayoritas. Apa ada kota atau kabupaten yang $100 \%$ orangnya homogen? Kan tidak ada.

Beberapa waktu lalu, terdapat spanduk PSI hoaks yang menyatakan bahwa PSI mendukung hak-hak kelompok LGBT. Sebagai partai yang mengecam aksi intoleransi, Bagaimana Anda menyikapi hal ini?

Sikap kita clear, semua orang berhak untuk hidup aman di Indonesia, tidak boleh di persekusi. Itu sikap kami.

\footnotetext{
${ }^{4}$ (Buehler, 2011)
} 
Belum lama, PSI mengeluarkan iklan yang mendukung ekspor sawit untuk memperkuat ekonomi Indonesia. Namun, perkebunan sawit terbukti menjadi salah satu faktor dalam penggundulan hutan. Di era dimana pembudidayaan lingkungan adalah isu yang dijunjung tinggi. Bagaimana kita dapat memperkuat ekonomi Indonesia sembari menjaga atau melestarikan lingkungan?

Memang harus ada aturannya, sekarang ini ekspor sawit sudah sangat ketat aturannya. Kalau mau diterima di pasar Eropa, mereka punya aturan bahwa praktik harus sustainable, tidak boleh memperkerjakan anak kecil, tidak merusak lingkungan dan sebagainya. Jadi aturannya sudah dibuat ketat. Yang perlu kita lakukan adalah jangan melihat ini sebagai hitam dan putih, tapi justru yang diarahkan adalah agar prosesnya lebih sustainable.

Kalau membicarakan pelestarian lingkungan ya, kita kalau membuat jalan itu membabat hutan, agar transportasi desa lebih lancar. Tapi kalau kita tidak ingin ada lingkungan yang diubah sama sekali kan berarti tidak membuat jalan, tidak membuat tempat tinggal dan sebagainya, apa mau seperti itu? Kan harus ada. Segala sesuatu ditempatkan pada proporsinya, artinya jangan kemudian serta merta membabi buta, menolak industri kelapa sawit. Ketika itu justru sudah ada aturannya juga. Salah satu caleg kami, Silverius Oscar Unggul mengadvokasi petani, jadi bukannya melarang mereka untuk menjadi petani sawit, tapi diajarkan bagaimana caranya agar memperhatikan aspek-aspek sustainability. Agar setelah itu pupuknya harus baik dan sebagainya, jadi harus berimbang. Aturan di luar negeri itu ketat sekali, itu harus dipenuhi. Kita perlu edukasi terus agar sustainability-nya terjaga.

PSI adalah partai yang sangat anti dengan korupsi, bahkan menyatakan siap disadap KPK seperti dikatakan oleh juru bicara PSI, Mikhail Gorbachev. Namun salah satu kader pilihan partai ini (Sudarmo, Kalimantan Barat) terbukti melakukan aksi tersebut meski memiliki sistem pemberantasan korupsi yang cukup ketat. Bagaimana sistem ini dapat diperkuat lagi?

Jadi sistem seleksi di PSI berlapis, kan ada juri independen. Selama proses penjurian pun kita undang orang-orang untuk meliput. Rata-rata media mainstream kita undang, termasuk media online. Bahkan media kami berikan kesempatan untuk masuk kedalam ruang penjurian untuk observasi, rekamannya juga ada di media sosial dan sebagainya. Kita melibatkan tokoh-tokoh independen untuk melakukan penjurian. Setelah itu kita lempar lagi ke publik, mereka wajib mencari dukungan dan sebagainya agar sosok ini beredar di masyarakat bahwa ia sedang nyaleg. Supaya, kalau ada yang tahu bahwa ia bermasalah, misalnya hutang tidak dibayar, menipu, atau melakukan kekerasan dalam rumah tangga, ada yang komplain. Fase ini sudah kita lakukan. Nah, kalau lulus wawancara dengan juri independen dan tidak ada komplain dari masyarakat, kita akan loloskan sebagai calon legislatif. Selain itu, kami juga cek SKCK (Surat Keterangan Catatan Kepolisian), artinya tidak dalam kasus pidana dan sebagainya. Kalau ia sedang dalam proses pidana, SKCK tidak akan keluar. Kalau semua sudah dipenuhi, kan kita tidak bisa meramal masa depan.

Tapi sudah kita buat dalam kontrak peraturannya, untuk saling menjaga. Yang bisa diperiksa kan yang sudah terjadi, yang belum kan kita tidak bisa cek, sehingga kita membuat legal agreement yang menyatakan bahwa, Anda bisa dipecat jika bolos lebih dari 10\%, melakukan kekerasan dalam rumah tangga, narkotika, terorisme, intoleransi, korupsi. Saat kader kami menjadi tersangka, kami akan pecat; tidak menunggu inkrah. Dia sudah dipecat, tetapi apa kemudian bisa di cap satu organisasi itu sama dengan dia? Bagaimana di partai-partai lain? 
Biasanya menunggu inkrah dan setelah masuk penjara, dicalonkan kembali sebagai caleg. Semua partai kecuali PSI dan Nasdem mencalonkan mantan napi korupsi.

\section{Selain itu, Gorbachev juga membuat poin yang cukup penting, bahwa melalui revisi UU KPK, DPR malah menambahkan undang-undang yang melemahkan gerakan pemberantasan korupsi. Bagaimana Anda menanggapi isu ini?}

Kembali lagi, yang membuat revisi undang-undang KPK sekarang siapa? Partai yang sekarang kan? Makanya harus dibenahi mulai dari manajemen partainya. Dari seleksinya lah. Yang lucu, kan KPK ini paling banyak menangkap anggota DPR, tetapi yang memilih KPK siapa? DPR. Jadi memang problem. Makanya, kami memilih untuk berjuang dari dalam. Kita harus buat partai, kita harus bisa masuk dan mempengaruhi proses legislasi, setidaknya menyuarakan. Target kami untuk masuk kali ini belum bisa menang voting, tetapi kita harus berisik, melakukan disrupsi, agar semua teman-teman media dan masyarakat sipil tahu, kalau peraturan-peraturan aneh seperti ini sedang dibuat.

Lihat peristiwa Angket KPK yang lalu, ketika ada usaha melemahkan KPK. PDIP ikut disitu, Golkar ikut disitu, bahkan inisiatornya PDIP, jadi masyarakat harus mengerti bahwa kita kalau ingin berjuang harus masuk dalam argumen, paling tidak untuk membuat berisik dan teman-teman media terus mengawal. Supaya publik tahu, kalau tidak ya lolos terus. Yang buat siapa undang-undang itu? Ya DPR yang sekarang ini, yang mayoritas dari mereka, 90\% mencalonkan diri kembali. Kan parah sekali.

Banyak partai atau caleg yang mengincar suara millennial namun sekedar melalui slogan-slogan "kekinian" di banner dan poster tanpa mempunyai kebijakan spesifik yang melibatkan atau menguntungkan millennial. Tapi PSI menggunakan jargon "Bro" dan "Sis" dan dibilang tidak relevan atau "trying too hard". Sebagai partai "anak muda", apa yang membedakan PSI dari sejumlah partai lain yang hanya mengejar suara?

Kalau panggilan "bro" dan "sis" dari awal karena kita ingin egaliter. Kita kan beragam, pada sebuah pertemuan awal, kita bingung. Ini mas siapa ya? Oh, ternyata dari Batak, Batak kan bukan mas, tapi bang. Kita ngobrol dengan orang lain lagi, juga tidak tahu namanya siapa karena masih perkenalan, ternyata dari Padang, ada uda, uni. Kan tidak bisa semuanya dibuat Jawa, dengan mas atau mbak. Kita sempat bingung bagaimana memanggil satu sama lain, ya sudahlah kita buat "bro" dan "sis" saja. Kan "bro" itu brother, saudara laki-laki, "sis" itu sister, saudara perempuan, jadi itu saja. Ternyata, dalam penerapannya terasa sekali mencairkan suasana. Karena kita tidak perlu terlalu akrab, langsung saja bro! Langsung sejajar. Seperti contohnya, saya dan Tsamara (Amany), berjarak umur 10 tahun lebih, tetapi kalau kita panggil "kakak" atau "adik" langsung terdengar jelas perbedaannya. Kalau saya panggil "sis!" gitu kan tidak. Disini ya begitu, mau staff magang, mau OB, semua manggil saya sis, jadi langsung sejajar. Itulah semangat awalnya.

Kemudian, 65\% caleg kita millennials, tidak by design ya memang karena kita banyak di media sosial backbone-nya, jadi orang lebih banyak tahu saat kita membuka pendaftaran caleg, alhasil setelah proses seleksi, 65\% caleg kita millennials. Program-program kita untuk anak muda juga beragam, pembebasan pajak untuk warga muda (pendapatan minimum Rp 7,5 untuk dikenakan pajak penghasilan), kontribusi ini kecil tetapi anak-anak muda dapat menggunakan dana tambahan itu untuk kesehatan, kualitas hidup dan sebagainya, jadi memberi kesempatan mereka untuk bertumbuh, jangan masih kecil sudah dikenakan pajak. 


\section{PSI adalah salah satu partai yang mendengarkan suara-suara anak muda, seperti persentase caleg millennials yang mencapai $65 \%$. Apakah suara mereka sudah cukup untuk dibawa untuk visi negara atau masih perlu dikembangkan lagi?}

Caleg itu kita tidak mencari orang yang paling pintar atau paling tahu. Caleg adalah wakil rakyat. Jadi fungsinya adalah harus kerja, harus datang, harus mendengar masukan. Kita tidak mencari orang terpintar, tapi kita butuh orang yang mau menjadi jembatan antara negara dan rakyatnya. Mereka bisa mendengarkan kemauan rakyat, kalau akademisi bilangnya begini, rakyatnya mau begini, titik tengahnya dimana?

Kita tidak mencari seorang doktor atau profesor yang pintar dan memikirkan solusi untuk semua yang terbaik untuk negara, kan tidak begitu. Dalam proses undang-undang kan banyak melakukan rapat dengar pendapat, kita ajak bicara lah komunitas, pengusaha, anak muda, kami juga undang akademisi. Dari semua itu kita mencari titik temunya dimana, kalau datang rapat saja tidak, dan datang tidur? Mau sepintar apapun ya percuma. Kita bukan mencari orang yang paling pintar, mungkin saya harus menanyakan kembali. Anak muda bisa apa? Masih muda. Kita juga mencari karyawan harus yang berpengalaman. Masalahnya, itu tidak menjadi ukuran karena kami mencari orang yang mau jadi orang yang mendengar, orangorang yang bekerja. Kita ini kan negara berkembang.

\section{PSI sangat mendukung Pak Jokowi, tetapi Pak Jokowi pun masih mempunyai banyak kekurangannya, Bagaimana Anda melihat kedua kandidat dalam kampanye pemilu tahun ini?}

Kalau untuk saya, Pak Jokowi PR-nya banyak, peninggalannya banyak sekali dan tidak bisa langsung sekali jadi. Tapi saya lihat progress-nya ada kok, bisa menyadari intoleransi, dari semua presiden hanya Pak Jokowi yang berani membubarkan organisasi HTI (Hizbut Tahrir Indonesia), dan itu sedang ia bayar sekarang. Terkena isu anti Islam. Terkait isu HAM, jika dihubungkan dengan kebebasan beribadah yang seperti saya bilang. Kita mempunyai masalah bahwa yang melakukan diskriminasi ada di level bawah juga. Kita sudah otonomi daerah, sudah bukan sentralisasi lagi. Sehingga Pak Jokowi tidak bisa dong mengurus semua sampai kabupaten, kan tidak bisa begitu. Maka dari itu kita butuh orang-orang yang di level kabupaten, provinsi dan lain-lain yang bagus. Selain itu, jika peraturan yang bermasalah di kabupaten level kota sampai provinsi. Sejak dua tahun lalu, kementerian dalam negeri sudah tidak bisa mencabut peraturan bermasalah, karena sudah dibatalkan oleh MK (Mahkamah Konstitusi). Sehingga, kalau ada peraturan diskriminatif, kok dibiarkan? Karena memang tidak bisa. Tadinya bisa, ada ribuan aturan yang ingin diregulasi oleh Pak Jokowi, tapi dibawah justru malah mempersulit. Nah, ini tidak bisa langsung dibatalkan, karena mereka sudah gugat ke MK. Makanya, kita butuh orang-orang terbaik sesuai visi kami, yang mempunyai kompetensi, siap melayani publik, bekerja terbuka, apapun suku agama dan rasnya masuk ke politik. Kalau tidak, karena sistem kita sudah desentralisasi dan otonomi daerah, mau punya presiden sebagus apapun tidak akan selesai permasalahannya, kenapa? Karena itu masalah datang dari pemerintahan daerah juga.

Salah satu keluhan yang paling banyak masuk dalam Komnas HAM itu tentang pemerintah daerah. Masalah ini harus diatasi, dan apa pintunya? Politik. Karena, siapa yang mengajukan bupati? DPRD? Tiket bupati atau walikota siapa? Kalau tidak independen kan partai. DPRD yang mengisi harus orang partai, jadi ujungnya selalu mengarah ke situ. 


\section{Kalau seandainya kalah nanti, apa yang akan terjadi dengan visi dan misi PSI?}

Tetap akan berjuang. Sekarang ada banyak hoax yang beredar, PSI katanya ingin memecah suara Pak Jokowi dan sebagainya. Tidak kok, memang ada keresahan itu, kami bentuk nyata dari keresahan itu. Kami tadinya orang-orang yang mempunyai pekerjaan. Saya mempunyai pekerjaan baik di media, teman-teman yang pengacara dan lain-lain yang masih kerja sampai sekarang, dan hidupnya tidak di politik. Namun kita mempunyai keresahan yang tidak bisa dijawab oleh partai-partai sekarang, hanya mencari aman, jadi kami memutuskan untuk maju. Kalau kita tidak berhasil kali ini, kita akan tetap berjuang. Akan lebih susah, kenapa? Mumpung sekarang kita mempunyai presiden bagus, Pak Jokowi, hanya dia yang berani membubarkan HTI, kalau kita menunggu 2024, Pak Jokowi sudah tidak ada, tidak bisa mencalonkan diri lagi. Lalu siapa? Sekarang yang terlihat ingin maju. Ada Sandiaga Uno, jika Pak Jokowi menang lagi berarti Sandi kan kalah, mungkin Pak Prabowo pemilu selanjutnya sudah lelah mungkin ya. Mungkin juga Anies (Baswedan), mungkin pemilik partai lain, ada AHY (Agus Harimurti Yudhoyono), ia juga memimpin partai demokrat. Nah orang-orang ini hari ini kompromistis tidak tegas pada kelompok intoleran. Kalau PSI baru memulai perjuangan 2024, sementara counterpart-nya saat ini saja tidak memperlihatkan sikap yang tegas terhadap intoleransi, pasti susah. Waktunya adalah sekarang, selagi presiden kami masih mempunyai misi yang sama.

\section{Penutup}

"Saya ingin menjadikan Indonesia menjadi rumah yang nyaman bagi siapa saja, tidak peduli apa suku, ras dan agamanya. Tidak peduli apakah dia perempuan atau laki-laki. Tidak peduli status sosial dan ekonominya. Rumah yang sama-sama kita jaga. Rumah yang selalu samasama kita perbaiki hari ke hari." ungkap Grace. ${ }^{5}$

Grace terbilang sosok yang berani dalam kancah politik praktis Indonesia. Keberanian Grace mendirikan partai politik baru bernama PSI patut diapresiasi semadyana. Tak dimungkiri, selain belakangan kepercayaan masyarakat terhadap partai politik merosot tajam, juga faktor personalitas Grace sebagai perempuan beretnis China serta identitasnya sebagai pemeluk Kristen menjadi sisi tersendiri. Belum lagi rekam jejak pemilik tinggi $155 \mathrm{~cm}$ dan berat $46 \mathrm{~kg}$ tersebut yang pernah tampil sebagai 100 sexiest women di For Him Magazine (FHM) pada 2009, majalah yang karib dengan kesan seksi.

Bekal tersebut cukup membuat Grace babak belur sebelum bertanding. Walau demikian, dia tak takut terpelanting. Grace tetap yakin untuk terus maju. Pelan-pelan dirinya berusaha memimpin partai yang didirikan bersama rekan-rekannya dengan semangat baru. PSI dibangun sebagai wadah perjuangan guna mewujudkan angan Grace agar keseharian masyarakat Indonesia menjadi harmonis, saling mengapresiasi kesamaan sekaligus menghormati ketidaksamaan. Dalam obrolan berikut, perempuan kelahiran 4 Juli 1982 ini berbagi pandangan mengenai makna kemerdekaan, masalah yang diprioritaskan untuk segera dituntaskan bersama, juga angan terbesar untuk Indonesia.

Sayang, raihan 179.949 suara dari Daerah Pemilihan 3 DKI Jakarta (Jakarta Utara, Jakarta Barat dan Kepulauan Seribu) tak membuat Grace menjadi anggota legislatif seiring kegagalan PSI menembus ambang batas. Walau begitu, berkat kepemimpinan Grace selama mendirikan, membangun, serta mengembangkan PSI, dirinya menerima beberapa apresiasi,

\footnotetext{
5 (Setiawan, Perjuangan Angan Perempuan, 2018)
} 
seperti Globe Asia '99 Most Powerful Woman 2017'; diundang menjadi pembicara pembuka dalam "The 2019 Indonesian Elections: Electoral Accountibilty and Democratic Quality" di University of Melbourne" pada 6-7 Agustus 2019 dengan menyampaikan ceramah berjudul "Defending Democracy"; serta diundang sebagai satu-satunya peserta dari Indonesia di forum

'Munich Young Leaders (MYL) 2020' di di Munich, Jerman, pada 13-16 Februari 2020. ${ }^{678}$

\section{Referensi}

Buehler, M. (2011, Agustus 29). Partainya Sekuler, Aturannya Syariah. Majalah TEMPO, hal. 74-5.

GlobeAsia. (2017, Oktober 13). GlobeAsia's 99 Powerful Women-2017. https://www.globeasia.com/cover-story/globeasias-99-powerful-women-2017/.

Körber-Stiftung. (2020, Februari 17). Munich Young Leaders at the Munich Security Conference. https://www.koerber-stiftung.delen/munich-young-leaders/newsdetails/munich-young-leaders-at-the-munich-security-conference-1969.

Setiawan, A. R. (2018, Januari 16). Amazing Grace. https://alobatnic.blogspot.com/2018/01/amazing-grace.html.

Setiawan, A. R. (2018, Desember 17). Grace Natalie, PSI, Poligami. https://alobatnic.blogspot.com/2018/12/grace-natalie-psi-poligami.html.

Setiawan, A. R. (2018, Juni 13). Perjuangan Angan Perempuan. https://alobatnic.blogspot.com/2018/06/perjuangan-angan-perempuan.html.

Setiawan, A. R. (2019, April 12). Q \& A. Grace Natalie Louisa. [interview]. https://alobatnic.blogspot.com/2019/04/grace-natalie-louisa.html.

The University of Melbourne. (2019, Agustus 5). The 2019 Indonesian Elections: Electoral Accountability and Democratic Quality. https://arts.unimelb.edu.au/_data/assets/pdf_file/0019/3128311/IDeHaRI-2019Workshop-Program-Final.pdf.

\footnotetext{
${ }^{6}$ (GlobeAsia, 2017)

${ }^{7}$ (The University of Melbourne, 2019)

${ }^{8}$ (Körber-Stiftung, 2020)
} 